\title{
Efficient identification of novel mutations in patients with limb girdle muscular dystrophy
}

\author{
Steven E. Boyden - Mustafa A. Salih - Anna R. Duncan - Alexander J. White • \\ Elicia A. Estrella $\cdot$ Stephanie L. Burgess $\cdot$ Mohammed Z. Seidahmed $\cdot$ \\ Abdullah S. Al-Jarallah • Hisham M. S. Alkhalidi • Waleed M. Al-Maneea • \\ Richard R. Bennett • Salem H. Alshemmari • Louis M. Kunkel • Peter B. Kang
}

Received: 24 May 2010 / Accepted: 22 June 2010 / Published online: 13 July 2010

(C) The Author(s) 2010. This article is published with open access at Springerlink.com

\begin{abstract}
Limb girdle muscular dystrophy type 2 (LGMD2) is a genetically heterogeneous autosomal recessive disorder caused by mutations in 15 known genes. DNA sequencing of all candidate genes can be expensive and laborious, whereas a selective sequencing approach often fails to provide a molecular diagnosis. We aimed to efficiently identify pathogenic mutations via homozygosity mapping in a population in which the genetics of LGMD2 has not been well characterized. Thirteen consanguineous families con-
\end{abstract}

Steven E. Boyden and Mustafa A. Salih contributed equally to this

work.

Electronic supplementary material The online version of this article (doi:10.1007/s10048-010-0250-9) contains supplementary material, which is available to authorized users.

S. E. Boyden · A. R. Duncan · A. J. White · E. A. Estrella •

S. L. Burgess · R. R. Bennett - L. M. Kunkel - P. B. Kang

Program in Genomics, Division of Genetics,

Children's Hospital Boston,

Boston, MA, USA

S. E. Boyden · L. M. Kunkel

Department of Genetics, Harvard Medical School,

Boston, MA, USA

M. A. Salih

Department of Pediatrics, Division of Neurology,

College of Medicine and King Khalid University Hospital,

King Saud University,

Riyadh, Kingdom of Saudi Arabia

M. Z. Seidahmed • W. M. Al-Maneea

Department of Pediatrics, Security Forces Hospital,

Riyadh, Kingdom of Saudi Arabia

A. S. Al-Jarallah

Department of Cardiac Sciences, College of Medicine,

King Saud University,

Riyadh, Kingdom of Saudi Arabia taining a proband with LGMD2 were recruited from Saudi Arabia, and for 11 of these families, selected individuals were genotyped at 10,204 single nucleotide polymorphisms. Linkage analysis excluded all but one or two known genes in ten of 11 genotyped families, and haplotype comparisons between families allowed further reduction in the number of candidate genes that were screened. Mutations were identified by DNA sequencing in all 13 families, including five novel mutations in four genes, by sequencing at most two

H. M. S. Alkhalidi

Department of Pathology, College of Medicine,

King Saud University,

Riyadh, Kingdom of Saudi Arabia

S. H. Alshemmari

Department of Medicine, Faculty of Medicine, Kuwait University, Kuwait City, Kuwait

\section{M. Kunkel}

The Manton Center for Orphan Disease Research,

Children's Hospital Boston,

Boston, MA, USA

\section{M. Kunkel}

Howard Hughes Medical Institute, Children's Hospital Boston,

Boston, MA, USA

P. B. Kang $(\bowtie)$

Department of Neurology,

Children's Hospital Boston and Harvard Medical School,

300 Longwood Avenue,

Boston, MA 02115, USA

e-mail: peter.kang@childrens.harvard.edu 
genes per family. One family was reclassified as having a different myopathy based on genetic and clinical data after linkage analysis excluded all known LGMD2 genes. LGMD2 subtypes A and B were notably absent from our sample of patients, indicating that the distribution of LGMD2 mutations in Saudi Arabian families may be different than in other populations. Our data demonstrate that homozygosity mapping in consanguineous pedigrees offers a more efficient means of discovering mutations that cause heterogeneous disorders than comprehensive sequencing of known candidate genes.

Keywords Limb girdle muscular dystrophy · Mutations . Linkage analysis $\cdot$ Homozygosity mapping .

Consanguineous · Saudi Arabian

\section{Introduction}

Limb girdle muscular dystrophies are a heterogeneous group of disorders, with the autosomal recessive type 2 (LGMD2) caused by mutations in at least 15 genes $[1,2]$. Characterization of the mutational spectrum of a disease in diverse populations is necessary to understand its pathogenesis and epidemiology. The frequencies of different LGMD2 subtypes and mutations vary considerably by population [1], but to our knowledge, the genetic profile of LGMD2 in Saudi Arabian patients has not been previously described. However, it can be costly and time consuming to screen all known LGMD2 genes (TTN alone has at least 312 exons), and screening only the seven most commonly mutated genes can fail to yield a mutation in approximately $30-40 \%$ of patients [3, 4].

Homozygosity mapping is an effective technique for localizing rare recessive mutations, as consanguineous pedigrees provide disproportionately high power for linkage analysis relative to the number of individuals genotyped [5]. In addition, high-density microarrays that assay thousands of single nucleotide polymorphisms (SNPs) allow a more informative and inexpensive genomewide linkage scan than conventional microsatellite panels [6]. We hypothesized it would be cost effective to focus the discovery of pathogenic LGMD2 mutations by performing SNP-based linkage analysis on consanguineous families, including those insufficiently informative to achieve suggestive or significant LOD scores. Here, we report the discovery of five novel mutations in four genes via homozygosity mapping in 11 Saudi Arabian families, accomplished at a fraction of the cost required to sequence all 15 LGMD2 genes.

\section{Materials and methods}

Thirteen families of Saudi Arabian descent in which patients appeared to be affected with LGMD2 were recruited via King Khalid University Hospital and Security Forces Hospital, Riyadh, Saudi Arabia. Written informed consent was obtained for all subjects, and de-identified genomic DNA samples were transferred to Children's Hospital Boston, in accordance with the Institutional Review Boards of the above institutions. The presumed diagnosis of LGMD2 was made on the basis of clinical presentation, serum creatine kinase levels, and muscle biopsy findings (including immunohistochemistry when available), as summarized in Table 1 .

Samples from 11 families were genotyped at 10,204 SNPs using the GeneChip Human Mapping 10K 2.0 Array (Affymetrix). To minimize costs, we genotyped primarily affected individuals, with unaffected subjects genotyped as needed (Fig. 1). Genomewide multipoint parametric linkage scans were performed using MERLIN v1.1.2 [7]. The disease allele frequency was set to 0.0001 , and we used a full penetrance, zero phenocopy model. Marker map positions and Caucasian allele frequencies were provided by Affymetrix. The error checking and Pedwipe functions of MERLIN were used to remove unlikely genotypes. Based on results from families 1186-1191, families 12231229 were screened for mutations in SGCA (also known as adhalin) and FKRP prior to $10 \mathrm{~K}$ genotyping; two families (1224 and 1227) in which mutations were identified were therefore not genotyped. Amplification of candidate gene exons and splice junctions by polymerase chain reaction (PCR) and sequencing of purified products were performed by standard protocols, and sequence data were analyzed using Sequencher v4.8 (Gene Codes) and SeqScape v2.5 (Applied Biosystems). Mutations were genotyped in DNA samples from unrelated control subjects using Custom TaqMan SNP Genotyping Assays (Applied Biosystems). Multi-species sequence alignments were performed in ClustalW [8], and the impact of amino acid substitutions on protein function was predicted by PolyPhen [9].

\section{Results}

The clinical presentations and laboratory results were generally typical of LGMD2, except in the case of family 1223 , in which creatine kinase levels were not elevated and calf pseudohypertrophy was absent (Table 1). The kindreds 1186-1191 and 1223-1229 were consanguineous and displayed autosomal recessive inheritance (Fig. 1). Mutations were identified in all 13 families, and for the 11 genotyped families, the mutations were in genes implicated by homozygosity mapping (Table 2). Five families produced one or more linkage peaks that together contained a single known LGMD2 gene, including one family (1225) with a maximum LOD score of 1.8 in which we genotyped only two affected siblings. Four families generated linkage 


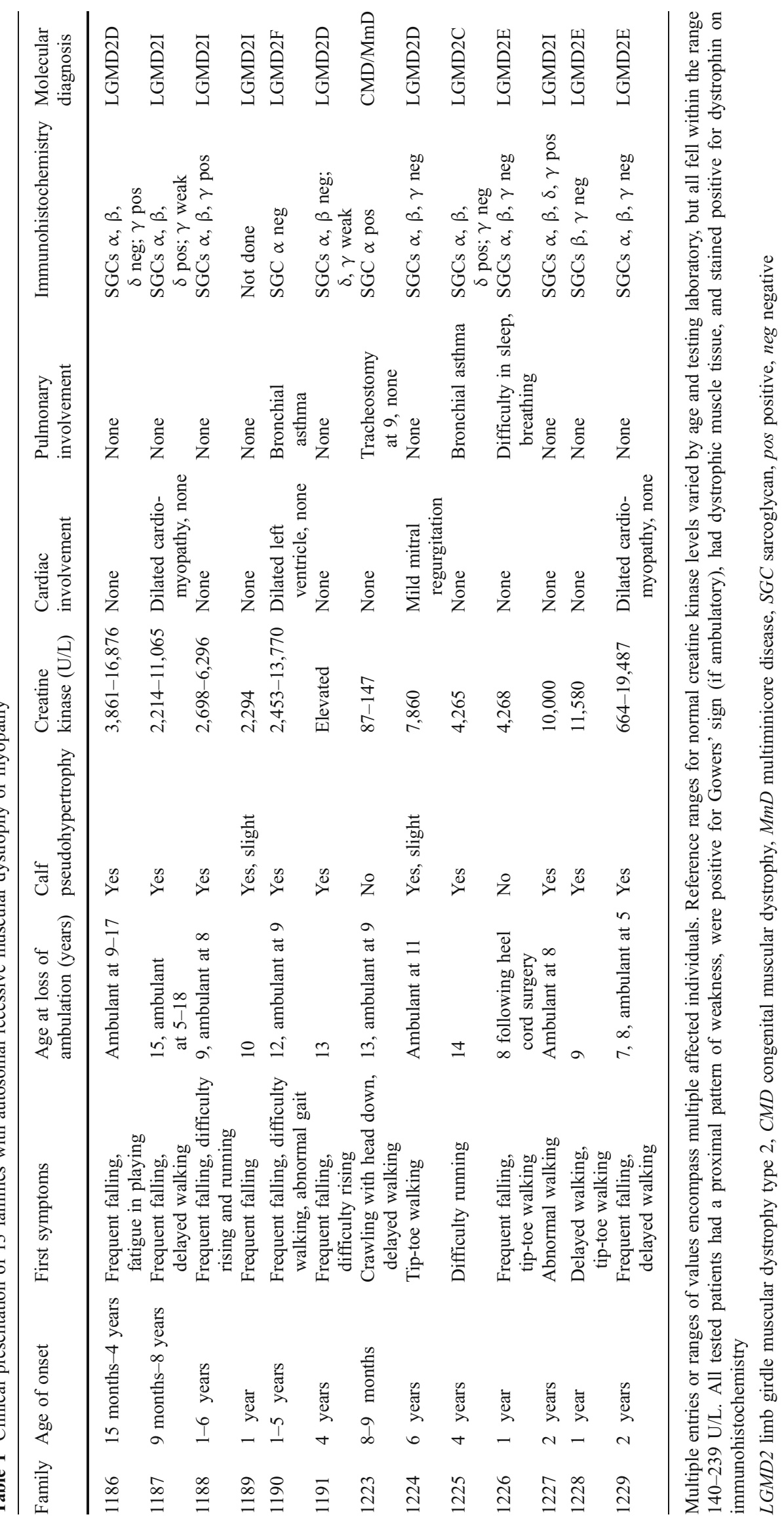


Fig. 1 Pedigrees of 13 families with autosomal recessive muscular dystrophy or myopathy. Squares males, circles females, filled symbols affected individuals, partially black-filled symbols obligate heterozygous carriers, partially gray-filled symbols possible heterozygous carriers, open symbols unaffected individuals. Double bars represent consanguineous unions. Asterisks denote individuals genotyped for genomewide linkage analysis
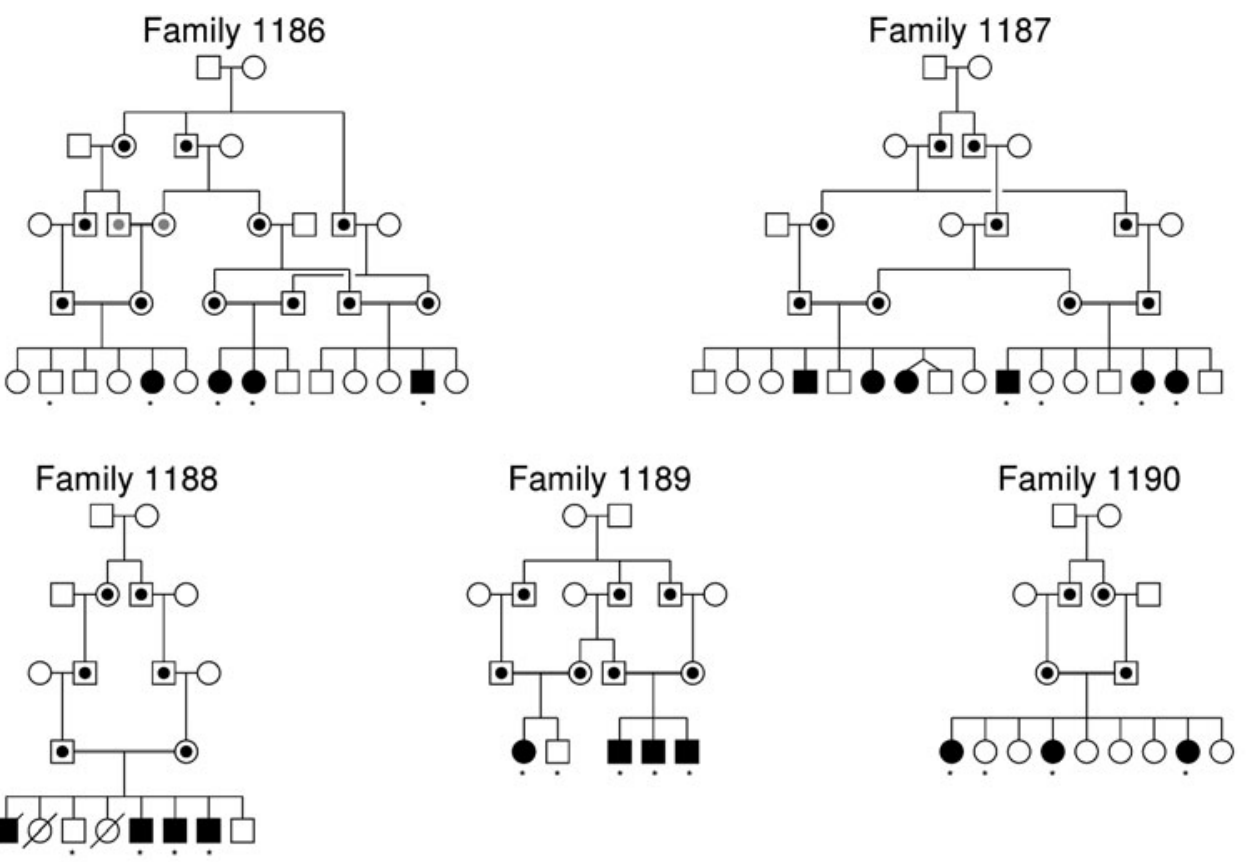
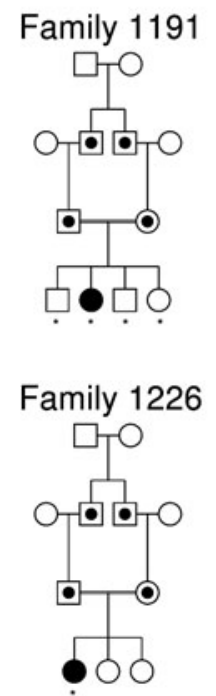
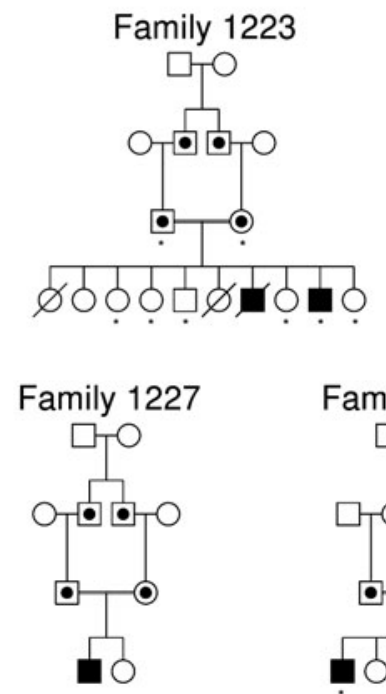

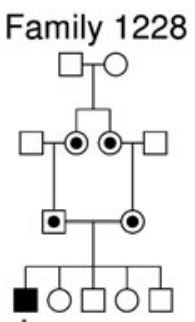

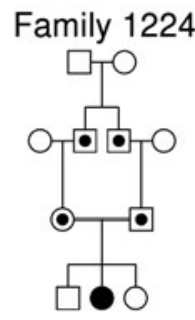

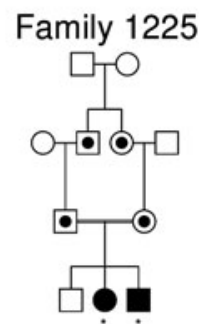

peaks containing two known LGMD2 genes, including a family (1228) with a maximum LOD score of 1.2 in which only a single affected individual was genotyped. For three families in which two linked genes resided in different intervals, the LOD score was appreciably higher for the peak containing the gene in which a mutation was found. In family 1191, two linked genes in a single interval, $S G C A$ and TCAP, were both sequenced and TCAP was negative for mutations.

Family 1226 showed linkage at four known LGMD2 genes, but families 1226, 1228, and 1229 shared a haplotype in common across a portion of their linkage peaks containing $S G C B$ (Online Resource 1), allowing us to correctly predict that all three families carried the same ancestral mutation in $S G C B$ and thus avoid sequencing the other five total candidate genes. Two genotyped families with the c.941C $>\mathrm{T}$ (p.T314M) mutation in FKRP also shared an identical haplotype across FKRP (data not shown), again implying that these families inherited their mutation from a common ancestor. A third, ungenotyped family carried this novel mutation as well, suggesting that c.941C $>$ T may be a founder mutation in Saudi Arabia.

In the 11th genotyped family, 1223, preliminary linkage results from a single affected individual produced intervals containing CAPN3 and DYSF. The proband was homozygous for a mutation in DYSF, c.6062G>A (p.R2021Q), previously reported (as p.R2000Q) to be compound heterozygous in conjunction with a nonsense mutation in a family with Miyoshi myopathy [10]. However, c.6062G $>$ A was homozygous in a confirmed unaffected sibling in family 
Table 2 Results of linkage analysis and mutation screening

\begin{tabular}{|c|c|c|c|c|c|c|c|c|c|}
\hline Family & $\begin{array}{l}\text { Samples } \\
\text { genotyped }\end{array}$ & $\begin{array}{l}\text { Linked known } \\
\text { genes }\end{array}$ & $\begin{array}{l}\text { Maximum possible } \\
\text { LOD score }\end{array}$ & $\begin{array}{l}\text { Maximum actual } \\
\text { LOD scores }\end{array}$ & $\begin{array}{l}\text { Gene with } \\
\text { mutation }\end{array}$ & Mutation & $\begin{array}{l}\text { Amino acid } \\
\text { substitution }\end{array}$ & Novel? & $\begin{array}{l}\text { Controls } \\
\text { genotyped }\end{array}$ \\
\hline 1186 & 5 & $S G C A$ & 4.941 & 4.940 & $S G C A$ & c. $101 \mathrm{G}>\mathrm{A}$ & p.R34H & No & NA \\
\hline 1187 & 4 & $F K R P$ & 2.533 & 2.533 & FKRP & c. $941 \mathrm{C}>\mathrm{T}$ & p.T314M & Yes & 379 \\
\hline 1188 & 4 & FKRP, POMT1 & 3.135 & $3.132,2.240$ & $F K R P$ & c. $1012 \mathrm{G}>\mathrm{T}$ & p.V338L & Yes & 368 \\
\hline 1189 & 5 & $F K R P$ & 4.038 & 4.038 & $F K R P$ & c. $941 \mathrm{C}>\mathrm{T}$ & p.T314M & Yes $^{\mathrm{a}}$ & (379 above) \\
\hline 1190 & 4 & $S G C D$ & 2.533 & 2.533 & $S G C D$ & c. $97 \mathrm{C}>\mathrm{T}$ & p.R33X & Yes & NA \\
\hline 1191 & 4 & $S G C A, T C A P$ & 1.579 & 1.578 & $S G C A$ & c. $584+5 \mathrm{G}>\mathrm{A}$ & NA & Yes & 491 \\
\hline 1223 & 8 & SEPN1 & 1.829 & 1.828 & SEPN1 & c. $467 \mathrm{~T}>\mathrm{C}$ & p.L156P & Yes & 375 \\
\hline 1224 & 0 & NA & NA & NA & $S G C A$ & c. $101 \mathrm{G}>\mathrm{A}$ & p.R34H & No & NA \\
\hline 1225 & 2 & $S G C G$ & 1.806 & 1.804 & $S G C G$ & c.525del & p.F175LfsX20 & No & NA \\
\hline 1226 & 1 & $\begin{array}{c}S G C B, S G C A \\
T C A P, D Y S F\end{array}$ & 1.204 & $\begin{array}{l}1.204,1.162, \\
0.607\end{array}$ & $S G C B$ & c.541_551del & p.S181X & No & NA \\
\hline 1227 & 0 & NA & NA & NA & $F K R P$ & c. $941 \mathrm{C}>\mathrm{T}$ & p.T314M & Yes $^{\mathrm{a}}$ & (379 above) \\
\hline 1228 & 1 & $S G C B, S G C G$ & 1.204 & $1.202,0.662$ & $S G C B$ & c.541_551del & p.S181X & No & NA \\
\hline 1229 & 3 & $S G C B, P O M T 1$ & 2.408 & $2.408,1.359$ & $S G C B$ & c.541_551del & p.S181X & No & NA \\
\hline
\end{tabular}

LOD scores for each family are reported only for genomic intervals containing linked known genes, and are listed in the same order as those genes. A single interval contained both $S G C A$ and TCAP in families 1191 and 1226. All mutations were homozygous in affected individuals, heterozygous in obligate carriers, and absent from all genotyped controls. Mutations were detected in DNA; predicted mutations in protein sequence were inferred

$N A$ not applicable

${ }^{a}$ An additional occurrence of a novel mutation reported herein

1223 and was heterozygous in three of 368 unrelated Kuwaiti control subjects, indicating either that this variant is a benign polymorphism or is only pathogenic when combined with a more severe mutation. Genomewide genotyping of additional family 1223 members excluded both CAPN3 and DYSF by linkage, but a linked interval on chromosome 1 contained the gene SEPN1, in which mutations cause several muscle diseases, including congenital muscular dystrophy (CMD) and multiminicore disease $(\mathrm{MmD})[11,12]$. Though affected members of family 1223 showed the typical pattern of weakness for LGMD, careful review of their clinical data also revealed scoliosis, respiratory difficulty treated by tracheostomy, and focal areas of myofibrillar disorganization and Z-band streaming in biopsy tissue, consistent with a diagnosis of $\mathrm{CMD}$ or $\mathrm{MmD}$. We identified two novel homozygous missense variants in SEPN1 that segregated with the disease: c.467T $>\mathrm{C}$ (p.L156P) and c.1654G $>$ A (p.E552K). However, the c.1654G $>$ A variant was heterozygous in eight of 374 unrelated Kuwaiti controls, the p.E552 residue was not completely conserved (Online Resource 2), and the p.E552K substitution was predicted to be less detrimental by PolyPhen than p.L156P (data not shown). Together, these data strongly suggest that $\mathrm{c} .1654 \mathrm{G}>\mathrm{A}$ is an uncommon polymorphism and c.467T $>\mathrm{C}$ (p.L156P) is the pathogenic mutation in family 1223 .

Finally, mutations in two commonly mutated genes (SGCA and FKRP) were found in two additional families that were not subjected to linkage analysis. In total, we identified eight pathogenic mutations in six genes in 13 families, of which five mutations in four genes were novel, while three mutations were previously reported [13-15]. The three novel missense mutations were absent from at least 368 Kuwaiti control DNA samples, and the novel splice site mutation was absent from 386 Kuwaiti controls and 105 Southeastern European controls. All four novel pathogenic missense or splice mutations were completely conserved in all vertebrate species analyzed (Online Resource 2).

\section{Discussion}

We conducted, to our knowledge, the first genetic characterization of LGMD in a Saudi Arabian population. Seven cases of Miyoshi myopathy from Saudi Arabia have been described clinically, and though mutations were not identified in these patients [16], mutations in DYSF have since been shown to cause both Miyoshi myopathy and LGMD2B [17]. In our study, homozygosity mapping via linkage analysis was used to efficiently identify five novel and three known mutations in five commonly mutated LGMD2 genes ( $S G C A, S G C B, S G C D, S G C G$, and FKRP) and a congenital myopathy gene (SEPN1). Multiple alternatives to linkage analysis are frequently used for homozygosity mapping [2, 18, 19], usually because they are technically simpler or computationally faster than a linkage scan, especially with very large pedigrees or exceptionally 
dense marker panels [20]. However, for a trait for which many genes have been previously identified, the probability that any particular family will contain a mutation in a known gene is high, so in this scenario, it is likely more cost effective for pedigrees with known consanguinity to limit genotyping to only a select few informative individuals on the most inexpensive SNP-based platforms. Our study confirms that under these conditions, homozygosity mapping can be readily accomplished by standard parametric linkage analysis [21], which has the benefits over other methods of distinguishing blocks of autozygosity from blocks of uninformative markers (which are not uncommon on high density SNP arrays) when parents and/or unaffected siblings are genotyped, as well as providing a measure of the statistical significance of linkage peaks interpretable by conventional standards.

We further highlight the utility of linkage analysis as a screening method even in families of marginal informativity. Nine of 11 genotyped families produced maximum LOD scores below the threshold of 3.3 for significant genomewide linkage, and five of those families fell below the threshold of 1.9 for suggestive linkage [22]. Nevertheless, linkage analysis excluded at least 13 of the 15 known genes in nine of ten families with LGMD2, and the LOD scores favored a specific gene in four of five families in which multiple known genes were linked. Comparison of haplotype data in linkage peaks shared among families further improved the power of our analyses by identifying families with evidence of carrying the same mutation inherited from a common ancestor. Accordingly, a mutation was identified in nine of ten genotyped LGMD2 families by sequencing a single gene; we thereby saved considerably on time and sequencing costs by conducting linkage scans.

Surprisingly, none of the families showed linkage to CAPN3 or DYSF, though they are the two most commonly mutated genes among LGMD2 patients in some populations [3, 4, 23], suggesting that LGMD2 subtypes A and B may be less common in Saudi Arabia than elsewhere. Since both $C A P N 3$ and DYSF require at least 30 amplicons to sequence their exons, the cost of PCR and bidirectional Sanger sequencing of either one in a single patient exceeds the cost of processing one 10K SNP array $(\$ 280$ at Children's Hospital Boston), further illustrating the economy of our approach. Moreover, the exclusion of all 15 known LGMD2 genes in family 1223 and the subsequent discovery of mutations in the myopathy gene SEPN1 demonstrate the application of linkage analysis to assist in resolving ambiguous clinical diagnoses, which may help account for the high failure rate when searching for mutations by sequencing alone.

Another alternative to comprehensive sequencing is to attempt molecular diagnosis by protein analysis, as six of the seven most commonly mutated LGMD2 genes (CAPN3, DYSF, SGCA, SGCB, SGCD, and SGCG) encode proteins that are absent or severely reduced by immunoblot or immunohistochemistry in the corresponding LGMD2 subtypes [4]. While this strategy depends on the availability of well-preserved biopsy tissue, it may be inexpensive and effective in some cases and thus advantageous for non-consanguineous families or sporadic patients. However, protein-based diagnostic testing can be time consuming and laborious, require separate optimization of conditions for each test, or lead to ambiguous findings, as when a single missing sarcoglycan subunit causes disruption of other subunits. Like Sanger sequencing, protein assays involve individual testing of each hypothesis, and the frequency with which a particular test will succeed in identifying the molecular defect depends on the LGMD2 subtype distribution in the population. For infrequently studied populations, the distribution may be unknown or unusual, and for patients in which protein tests are unsuccessful, genetic analyses may then be necessary, possibly negating any initial cost savings.

By contrast, genomewide homozygosity mapping offers a single, unbiased, simultaneous test of all possible loci, and in cases where the most obvious candidate genes are excluded, linkage data can direct attention to novel genes or genes associated with similar phenotypes. While homozygosity mapping is most effective in families known to be consanguineous, it can also be applied successfully to outbred populations when higher density SNP arrays are used [24]. Homozygosity mapping may therefore provide a faster and less expensive approach to molecular diagnosis of genetically heterogeneous traits in many families than comprehensive screening of candidate genes by traditional sequencing methods.

Acknowledgments The authors thank the patients and their families for their participation in this study and Kyriacos Markianos for helpful discussions. This work was supported by K08 NS048180 (PBK), the Genise Goldenson Fund (PBK), the Howard Hughes Medical Institute (LMK), the Manton Center for Orphan Disease Research (LMK), and the Bernard and Alva B. Gimbel Foundation (LMK). Microarray genotyping and DNA sequencing experiments were performed in the Molecular Genetics Core Facility at Children's Hospital Boston, supported by NIH-P30-HD18655 through the Intellectual and Developmental Disabilities Research Center and NIH-P50-NS40828 through the Neuromuscular Disease Project.

Conflict of interest The authors declare that they have no conflict of interest.

Open Access This article is distributed under the terms of the Creative Commons Attribution Noncommercial License which permits any noncommercial use, distribution, and reproduction in any medium, provided the original author(s) and source are credited. 


\section{References}

1. Guglieri M, Straub V, Bushby K, Lochmuller H (2008) Limbgirdle muscular dystrophies. Curr Opin Neurol 21:576-584

2. Bolduc V, Marlow G, Boycott KM, Saleki K, Inoue H, Kroon J, Itakura M, Robitaille Y, Parent L, Baas F, Mizuta K, Kamata N, Richard I, Linssen WH, Mahjneh I, de Visser M, Bashir R, Brais B (2010) Recessive mutations in the putative calciumactivated chloride channel Anoctamin 5 cause proximal LGMD2L and distal MMD3 muscular dystrophies. Am J Hum Genet 86:213-221

3. Guglieri M, Magri F, D'Angelo MG, Prelle A, Morandi L, Rodolico C, Cagliani R, Mora M, Fortunato F, Bordoni A, Del Bo R, Ghezzi S, Pagliarani S, Lucchiari S, Salani S, Zecca C, Lamperti C, Ronchi D, Aguennouz M, Ciscato P, Di Blasi C, Ruggieri A, Moroni I, Turconi A, Toscano A, Moggio M, Bresolin N, Comi GP (2008) Clinical, molecular, and protein correlations in a large sample of genetically diagnosed Italian limb girdle muscular dystrophy patients. Hum Mutat 29:258-266

4. Fanin M, Nascimbeni AC, Aurino S, Tasca E, Pegoraro E, Nigro V, Angelini C (2009) Frequency of LGMD gene mutations in Italian patients with distinct clinical phenotypes. Neurology 72:1432-1435

5. Lander ES, Botstein D (1987) Homozygosity mapping: a way to map human recessive traits with the DNA of inbred children. Science 236:1567-1570

6. Sawcer SJ, Maranian M, Singlehurst S, Yeo T, Compston A, Daly MJ, De Jager PL, Gabriel S, Hafler DA, Ivinson AJ, Lander ES, Rioux JD, Walsh E, Gregory SG, Schmidt S, Pericak-Vance MA, Barcellos L, Hauser SL, Oksenberg JR, Kenealy SJ, Haines JL (2004) Enhancing linkage analysis of complex disorders: an evaluation of high-density genotyping. Hum Mol Genet 13:19431949

7. Abecasis GR, Cherny SS, Cookson WO, Cardon LR (2002) Merlin-rapid analysis of dense genetic maps using sparse gene flow trees. Nat Genet 30:97-101

8. Thompson JD, Higgins DG, Gibson TJ (1994) CLUSTAL W: improving the sensitivity of progressive multiple sequence alignment through sequence weighting, position-specific gap penalties and weight matrix choice. Nucleic Acids Res 22:4673-4680

9. Ramensky V, Bork P, Sunyaev S (2002) Human non-synonymous SNPs: server and survey. Nucleic Acids Res 30:3894-3900

10. Aoki M, Liu J, Richard I, Bashir R, Britton S, Keers SM, Oeltjen J, Brown HE, Marchand S, Bourg N, Beley C, McKenna-Yasek D, Arahata K, Bohlega S, Cupler E, Illa I, Majneh I, Barohn RJ, Urtizberea JA, Fardeau M, Amato A, Angelini C, Bushby K, Beckmann JS, Brown RH Jr (2001) Genomic organization of the dysferlin gene and novel mutations in Miyoshi myopathy. Neurology 57:271-278

11. Moghadaszadeh B, Petit N, Jaillard C, Brockington M, Roy SQ, Merlini L, Romero N, Estournet B, Desguerre I, Chaigne D, Muntoni F, Topaloglu H, Guicheney P (2001) Mutations in SEPN1 cause congenital muscular dystrophy with spinal rigidity and restrictive respiratory syndrome. Nat Genet 29:17-18

12. Ferreiro A, Quijano-Roy S, Pichereau C, Moghadaszadeh B, Goemans N, Bonnemann C, Jungbluth H, Straub V, Villanova M, Leroy JP, Romero NB, Martin JJ, Muntoni F, Voit T, Estournet B, Richard P, Fardeau M, Guicheney P (2002) Mutations of the selenoprotein $\mathrm{N}$ gene, which is implicated in rigid spine muscular dystrophy, cause the classical phenotype of multiminicore disease: reassessing the nosology of early-onset myopathies. Am J Hum Genet 71:739-749

13. Piccolo F, Roberds SL, Jeanpierre M, Leturcq F, Azibi K, Beldjord C, Carrie A, Recan D, Chaouch M, Reghis A et al (1995) Primary adhalinopathy: a common cause of autosomal recessive muscular dystrophy of variable severity. Nat Genet 10:243-245

14. Noguchi S, McNally EM, Ben Othmane K, Hagiwara Y, Mizuno Y, Yoshida M, Yamamoto H, Bonnemann CG, Gussoni E, Denton PH, Kyriakides T, Middleton L, Hentati F, Ben Hamida M, Nonaka I, Vance JM, Kunkel LM, Ozawa E (1995) Mutations in the dystrophin-associated protein gamma-sarcoglycan in chromosome 13 muscular dystrophy. Science 270:819-822

15. den Dunnen JT (2010) Leiden Muscular Dystrophy pages. Leiden University Medical Center. http://www.dmd.nl/. Accessed 6 April 2010.

16. Cupler EJ, Bohlega S, Hessler R, McLean D, Stigsby B, Ahmad J (1998) Miyoshi myopathy in Saudi Arabia: clinical, electrophysiological, histopathological and radiological features. Neuromuscul Disord 8:321-326

17. Liu J, Aoki M, Illa I, Wu C, Fardeau M, Angelini C, Serrano C, Urtizberea JA, Hentati F, Hamida MB, Bohlega S, Culper EJ, Amato AA, Bossie K, Oeltjen J, Bejaoui K, McKennaYasek D, Hosler BA, Schurr E, Arahata K, de Jong PJ, Brown RH Jr (1998) Dysferlin, a novel skeletal muscle gene, is mutated in Miyoshi myopathy and limb girdle muscular dystrophy. Nat Genet 20:31-36

18. Abu Safieh L, Aldahmesh MA, Shamseldin H, Hashem M, Shaheen R, Alkuraya H, Al Hazzaa SA, Al-Rajhi A, Alkuraya FS (2010) Clinical and molecular characterisation of Bardet-Biedl syndrome in consanguineous populations: the power of homozygosity mapping. J Med Genet 47:236-241

19. Harville HM, Held S, Diaz-Font A, Davis EE, Diplas BH, Lewis RA, Borochowitz ZU, Zhou W, Chaki M, MacDonald J, Kayserili H, Beales PL, Katsanis N, Otto E, Hildebrandt F (2010) Identification of 11 novel mutations in eight BBS genes by high-resolution homozygosity mapping. J Med Genet 47:262-267

20. Seelow D, Schuelke M, Hildebrandt F, Nurnberg P (2009) Homozygositymapper - an interactive approach to homozygosity mapping. Nucleic Acids Res 37:W593-W599

21. Kruglyak L, Daly MJ, Lander ES (1995) Rapid multipoint linkage analysis of recessive traits in nuclear families, including homozygosity mapping. Am J Hum Genet 56:519-527

22. Lander E, Kruglyak L (1995) Genetic dissection of complex traits: guidelines for interpreting and reporting linkage results. Nat Genet 11:241-247

23. Lo HP, Cooper ST, Evesson FJ, Seto JT, Chiotis M, Tay V, Compton AG, Cairns AG, Corbett A, MacArthur DG, Yang N, Reardon K, North KN (2008) Limb-girdle muscular dystrophy: diagnostic evaluation, frequency and clues to pathogenesis. Neuromuscul Disord 18:34-44

24. Hildebrandt F, Heeringa SF, Ruschendorf F, Attanasio M, Nurnberg G, Becker C, Seelow D, Huebner N, Chernin G, Vlangos CN, Zhou W, O'Toole JF, Hoskins BE, Wolf MT, Hinkes BG, Chaib H, Ashraf S, Schoeb DS, Ovunc B, Allen SJ, VegaWarner V, Wise E, Harville HM, Lyons RH, Washburn J, Macdonald J, Nurnberg P, Otto EA (2009) A systematic approach to mapping recessive disease genes in individuals from outbred populations. PLoS Genet 5:e1000353 